This is a post-peer-review, pre-copyedit version of an article published in Educational Studies in Mathematics. The final authenticated version is available online at:

https://www.springer.com/journal/10649 DOI: 10.1007/s10649-020-09992-x 


\begin{abstract}
Alison Barnes
Enjoyment in learning mathematics: Its role as a potential barrier to children's perseverance in mathematical reasoning
\end{abstract}

University of Brighton, School of Education, Brighton, UK a.barnes2@brighton.ac.uk

ORCiD Number: https://orcid.org/0000-0002-6841-5857 


\section{Enjoyment in learning mathematics: Its role as a potential barrier to children's perseverance in mathematical reasoning}

\section{Abstract}

Enjoyment in learning mathematics is often perceived to be a positive, desirable emotion in the learning process. However, the findings of this study indicate that it can act as a barrier to persevering in mathematical reasoning by reinforcing a focus on habitual behaviours and inhibiting self-regulatory behaviours. The study identifies implications for practitioners; children's limited perseverance in mathematical reasoning (PiMR) may be masked by expressions of enjoyment and willingness to keep striving. Hence, to notice children's barriers to PiMR, teachers may need to look for children's repetitious use of reasoning processes or limited movement between reasoning process rather than relying on emotion indicators or expressions of being stuck. The study focused on children, age 10-11, selected for their limited PiMR, and sought to better understand the conditions when difficulties encountered in mathematical reasoning became barriers to successful PiMR. Data, collected in two English schools by observation and interview, related to children's cognitive and affective responses and their active-goals. A tripartite psychological classification was used to analyse children's cognitive, affective and conative difficulties in mathematical reasoning and to analyse when these difficulties became barriers that children were unable to overcome.

Keywords: Perseverance in mathematical reasoning (PiMR), difficulty, emotion, affect, self-regulation, active-goal

\section{Introduction}

The idea of perseverance has gained popularity in education. In practice, this has resulted in generic strategies that, drawing broadly on Dweck's (2000) growth mindset theory, value effort by guiding students to push themselves and keep going. This guidance is commonly displayed on classroom walls, prompting student effort and perseverance across the curriculum; this raises questions about whether generic guidance on perseverance is applicable in mathematics learning. This study generated and analysed empirical data to better understand perseverance and its application in mathematical reasoning.

Reasoning is significant in learning mathematics. It is a skill on which children's use of mathematics is founded (Ball and Bass, 2003) and is central to forming and justifying mathematical arguments (Mueller, Yankelewitz and Maher, 2010). Ball and Bass (p. 28) argue that without reasoning, "mathematical understanding is meaningless". 
However, mathematical reasoning is not straightforward. A line of reasoned enquiry can trace a "zigzag" route (Lakatos, 1976, p. 42) necessitating repeated decision-making and overcoming being stuck (Mason, Burton and Stacey, 2010). Experiencing difficulty is not an unwelcome by-product of mathematics learning but a necessary component; Hiebert (2003) highlights the important role that struggle plays in constructing mathematical understanding. He argues that mathematics should be problematic for children, acknowledging that this stance is counter to the prevailing orthodoxy, that teachers are "encouraged to make mathematics less problematic for students" (p. 54, original emphasis). Whilst Mason et al. similarly celebrate the value of being stuck because of the opportunities it presents for learning, Williams argues that perseverance is needed when "mathematical situations are unfamiliar and a clear pathway is not apparent" $(2014$, p. 30).

Hence, when engaging in mathematical reasoning, struggle and overcoming difficulties should be part of the experience and perseverance is required to overcome the difficulties. However, when children find difficulties in mathematical reasoning insurmountable, these become barriers to their capacity to persevere in mathematical reasoning.

This article reports on a study of the concept of perseverance in mathematical reasoning (PiMR) and the difficulties that children aged 10-11 in two English primary (elementary) schools encountered during activities involving mathematical reasoning. The study sought to understand the conditions when difficulties encountered in mathematical reasoning became barriers to successful PiMR. The article therefore addresses the research questions: what difficulties do children need to overcome in order to persevere in mathematical reasoning? What are the conditions under which the difficulties become barriers to PIMR?

Perseverance is an aspect of the conative domain (Huitt and Cain, 2005). Snow, Corno and Jackson (1996) state that conation concerns motivation and volition, in which motivation relates to predecisional processes including goal formation, and volition relates to enactment and involves maintaining purposive, conscious striving towards a goal. I applied these volitional aspects to define PiMR as:

Striving to pursue a line of mathematical reasoning, despite difficulty or delay in achieving success.

Difficulties encountered in persevering in mathematical reasoning might manifest in three ways. First, they may derive from the cognitive aspects of mathematical reasoning. Second, there is known to be interplay between cognition and affect during mathematical activity (Barnes, 2019; Di Martino and Zan, 2011), in which, Hannula (2012) argues, emotions can focus and bias cognition. Hence difficulties could 
relate to affect during mathematical reasoning. Third, the conative aspects relating to perseverance may give rise to difficulties. Snow et al. (1996) assert that cognition, affect and conation should be understood in relation to each other rather than as isolated domains; hence a tripartite framework provides a useful approach to analyse difficulties that children encounter during mathematical reasoning.

As my study focused on children's responses in individual mathematics lessons, it concerned what Hannula (2012) describes as the state aspects of each psychological domain with their potential for rapid fluctuation, rather than the more stable trait aspects that develop over time. For example, in relation to the affective domain, Hannula argues that a child's emotional state can change rapidly during a mathematical task, from, e.g., frustration to enjoyment, whilst the child might generally approach mathematical tasks with a more stable emotional trait, such as apprehension towards problem-solving tasks. Fig. 1 illustrates the tripartite framework used in this study, which enabled examination of each domain in relation to mathematical reasoning and the related potential difficulties.

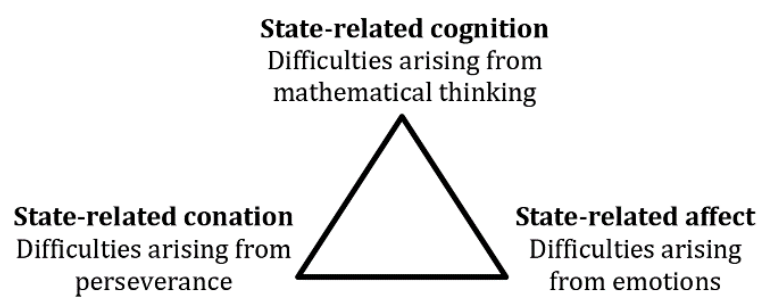

Fig. 1 Tripartite psychological classification of potential difficulties during mathematical reasoning

\section{Conceptual Framework}

The conceptual framework is structured in three sections. Each addresses a domain detailed in Fig. 1 in relation to mathematical reasoning and examines the difficulties that children need to overcome in order to persevere in mathematical reasoning.

\section{Cognition and cognitive difficulties in mathematical reasoning}

Drawing on Pólya's (1959) notion of plausible reasoning as a means of constructing mathematical thinking, I interpreted mathematical reasoning as:

The pursuit of a line of enquiry to produce assertions and develop an argument to reach and justify conclusions.

There is general agreement regarding the mathematical reasoning processes needed to pursue a line of enquiry (e.g., Ball and Bass, 2003; Mason et al., 2010). From this literature, I identified five key state- 
related cognitive processes: specialising (making trials), spotting patterns/relationships, conjecturing, generalising and forming convincing arguments.

The conjecturing process is central to mathematical reasoning (Mason et al., 2010; Stylianides, 2008). A conjecture is an idea that seems reasonable but whose truth it still to be established (Mason et al., p. 58). To create a conjecture, a relationship needs to be inducted and spotting patterns is central to this. For patterns to emerge examples need to be created; Mason et al. argue that examples are initially generated through random specialisation to get a feel for the problem. This process develops into systematic specialisation (Mason et al.) in which a system is applied to a sequence of trials to generate data from which patterns can emerge. The processes of specialising systematically, spotting patterns and forming conjectures facilitate generalising.

Whilst pattern spotting is a key process in formulating generalisations, to establish convincing arguments about why a generalisation is true, structural thinking, with its focus on the properties of a relationship, is required (Mason, Stephens and Watson, 2009). Stylianides (2008) argues that in school mathematics, formal logic or proof is not necessarily required; mathematical assertions can be supported by what Lithner (2008, p. 257) describes as "sensible" reasons in which arguments are anchored in the relevant mathematical properties and conclusions are warranted by drawing on relevant data.

Ellis (2007) identified two points during reasoning when children commonly become stuck. First, children encounter difficulty in utilising the patterns they have spotted as a platform for generalisation; Ellis (p. 195) argues that whilst children may recognise patterns, "they may not attend to those that are algebraically useful or generalizable". Second, difficulty arises in creating convincing arguments as to why a generalisation might be true. In addition, Reid (2002) found that children's reasoning in Grade 5 (age 10-11) was only partly mathematical. He argues that a difficulty was that the children did not expect to explain the reasons why a mathematical pattern occurs. Hence, there are at least three points of potential difficulty for children in pursuing a line of mathematical reasoning: the transitions from pattern spotting to generalising; from generalising to convincing; and the expectation to seek

justifications through forming convincing mathematical arguments about why a generalisation might be true.

\section{Affect and affective difficulties in mathematical reasoning}

Affect in this study concerns the state aspect of emotion with its propensity for rapid change. Goldin (2000) argues that affective systems can represent information, including states of feeling and the 
transformation of feelings based on cognitive incidents. He discusses two commonly experienced affective pathways during reasoning in problem-solving contexts. Each begins with feelings of curiosity and puzzlement as students begin the problem, followed by bewilderment as they seek effective problem-solving strategies. Here the pathways diverge. In one, choosing an effective strategy, rather than a method prescribed by the teacher, leads to feelings of encouragement, pleasure and elation as new insights arise. This culminates in satisfaction in the success of the solution and approach. A positive correlation is reported between trait-related affect and achievement (Hannula, 2019) and between enjoyment and achievement (Schukajlow, Leiss, Pekrun, Blum, Müller and Messner, 2012) and this seems to be reflected in this state-related affective pathway as insights correlate with pleasure.

In Goldin's second pathway, bewilderment does not result in students' choosing an effective strategy and frustration develops. If a way forward is not established, emotions become increasingly negative, leading to anxiety and even despair. This affective pathway can present a barrier to mathematical reasoning; Goldin (2000) argues that in response to this difficulty, students may endeavour to alleviate uncomfortable emotions, for example, by using rote procedures or avoidance strategies, neither of which is likely to result in mathematical reasoning.

These pathways illustrate bi-directional cognitive-affective interplay that reflect an embodied perspective of affect. Debellis and Goldin (2006) argue that affect is communicated through facial expressions, oral utterances, intonation, body gestures and position; this, Hannula (2012) asserts, provides a means to observe emotions during cognitive processes. This indicates that a multi-modal approach to collect affective data is appropriate (discussed in Methods).

\section{Conation and conative difficulties in persevering in mathematical reasoning}

Akin to other psychological domains, conation has trait and state aspects. Snow et al. (1996) argue that the trait aspects develop over time, for example, volitional dispositions to strive and self-regulate, and motivations. The related state aspects are acts of striving and self-regulating (Huitt and Cain, 2005; Tanner and Jones, 2003) and having goals that are "in-the-moment" (Goldin, Epstein, Schorr and Warner, 2011, p. 550) or "active" (Hannula, 2011, p. 45); I use the term active-goals to describe immediate rather than long term goals. These are pertinent in this study because they characterise the perseverance aspect of PiMR.

Children's active-goals during mathematical reasoning can be evidenced through the focus of their engagement. Fredricks, Blumenfeld and Paris (2004) state that engagement includes making contributions to discussion, focusing attention and adhering to classroom norms. In mathematical 
reasoning, children's engagement can be interpreted in at least three ways. First, through the focus of their attention on the mathematical concepts in which the reasoning is anchored (Lithner, 2008) or the mathematical processes required to construct a reasoned line of enquiry (Mason et al., 2010). Second, through their contributions to mathematical discussions stimulated by a reasoning activity. Observations of foci of children's engagement during mathematical reasoning can indicate their active-goals. In the third presentation of engagement, adhering to classroom norms, a child could appear to be engaged with the reasoning activity, for example by creating representations in concert with peers. However, in the absence of a focus on relevant mathematical concepts or reasoning processes, this appearance of activity engagement would be indicative of a barrier to PiMR.

Striving is pro-active and goal-oriented (Huitt and Cain, 2005). Striving towards the active-goal of forming and justifying generalisations necessitates the development of assertions and arguments. PiMR is the process of successfully striving towards these goals. This may be evident in observing children's reasoning processes and the movement between these, for example, from specialising and spotting patterns towards conjecturing, generalising and forming convincing arguments. Progression between reasoning processes requires the application of learning from one process to the next and the adoption of pro-active rather than reactive or habitual behaviour (Huitt and Cain; Tanner and Jones, 2003). If reactive or habitual behaviours are dominant during activities involving mathematical reasoning, striving might be interpreted as keeping going, irrespective of the quality of or findings from each try; this is what Williams (2014) refers to as persistence, not perseverance. Persistent behaviours in mathematical reasoning may limit the application of learning from trials, impede pattern spotting, conjecturing and generalising, and result in children's limited movement between reasoning processes or even stasis in one process. Persistence, with its characteristic habitual behaviours, is a potential barrier to PiMR. Pro-active behaviour that strives towards active-goals requires effective self-regulation as this is a process in which students' cognitions, behaviours and affects "are systematically oriented towards attainment of their goals" (Zimmerman and Schunk, 2011, p. 1). According to Özcan (2016), in mathematical reasoning, cognitive self-regulation requires reflection on the information generated and the value of the processes applied; this supports movement between reasoning processes towards generalising and forming convincing arguments. Goswami (2015) asserts that self-regulatory processes facilitate conscious inhibition or development of thoughts, feelings and behaviours; in PiMR this plays an important role in adjusting actions to overcome difficulties encountered. However, although selfregulation is an important aspect of PiMR, Goswami argues that it is not easy for children in the primary 
(elementary) phase to develop and apply; this limited or emerging self-regulation can be a barrier to children's successful PiMR.

Awareness of emotions can facilitate meta-affective responses. Debellis and Goldin (2006) assert that meta-affect, the self-regulatory aspect of affect, concerns the cognitive monitoring of emotions and emotional responses to emotions; for example, they argue that frustration can be experienced as pleasure because it suggests increased and interesting challenge, enabling alternative approaches to be sought. Malmivuori (2006) describes conscious monitoring of emotions and the subsequent cognitive actions taken as active regulation of affect. This meta-affective self-regulation can support successful PiMR; it facilitates using emotions, such as bewilderment, as a catalyst for reflection on and selfregulation of reasoning processes.

However, emotional awareness, whilst an important starting point for active regulation of affect, is not an automatic stimulus for cognition. Malmivuori (2006) articulates a second affective response, automatic affective regulation. In a limited self-regulatory system, habitual affective responses override self-regulation. For example, when stuck, frustration may be automatically accompanied by fear, impeding higher order mental processes. Malmivuori argues that automatic affective regulation can manifest in habitual behaviours such as defensive actions; consequently, automatic affective regulation may be a barrier to PiMR.

\section{Study Design}

This section addresses the study design, including selection of participants and mathematical activities, data collection and analytic methods, limitations and reliability checks.

The data reported here were part of a research study that sought to improve children's PiMR through teacher interventions; the interventions and their impact are reported in Barnes (2019). Eight children from two year 6 (age 10-11) classes in different schools in England participated. Hannula (2019) argues that children's mathematics-related affect declines with age during primary school. The 10-11 agegroup, the oldest in English primary schools, was selected for this study as the combination of declining affect and increasing curriculum demand created potential for children to encounter difficulties during mathematical reasoning.

The original study used an action research approach as it sought to apply "action strategies to bring about positive changes" (Somekh, 2006, p. 6) to children's PiMR. This article reports on one aspect of the original study; the conditions in which difficulties encountered in mathematical reasoning become 
barriers to children's PiMR. To examine data from the original study pertaining to this phenomenon, I drew on characteristics derived from Merriam's (1998) case study approach: the particular focus on the phenomenon, the rich, thick description of the phenomenon and the intention of illuminating understanding of the phenomenon. I use three vignettes to present data from four of the eight children relating to the phenomenon. Drawing on Ely, Vinz, Downing and Anzul (1997), the vignettes are used to present compact portrayals that highlight specific difficulties encountered by the children, and the conditions in which these became barriers to successful PiMR. Merriam (1995) argues that the use of the thick descriptions supports the reader to compare their own/other situations with the research to determine the transferability of the findings.

The two teachers were generalist primary (elementary) practitioners with mathematical subject and pedagogic expertise. This was significant as it reduced the possibility of the teachers' subject and/or pedagogic knowledge being a factor in children's difficulties in mathematical reasoning. The characteristics of each school (e.g., school type, location, cohort profile) were less significant in this study as this did not emerge in the literature as a potential factor impacting children's barriers to PiMR. Each vignette arose from a one-hour mathematics lesson. For each lesson, the teachers and I selected one activity (Table 1) based on three criteria: the activity afforded opportunities to pursue a reasoned line of enquiry culminating in forming generalisations with convincing arguments as to why it was true; it was at the appropriate level for the children in each class, and they had not previously engaged with the activity.

Table 1: Mathematical activities

\begin{tabular}{|l|l|l|}
\hline Magic Vs $^{1}$ & Paths around a pond $^{\text {Number differences }^{2}}$ \\
\hline $\begin{array}{l}\text { Arrange the numbers } \\
\text { 1-5 in a V so that } \\
\text { each arm of the } \mathrm{V} \\
\text { sums to the same } \\
\text { total. }\end{array}$ & $\begin{array}{l}\text { A square pond is surrounded by a } \\
\text { path that is 1 unit wide. Explore } \\
\text { what happens as the pond size } \\
\text { changes. }\end{array}$ & $\begin{array}{l}\text { Arrange the } \\
\text { numbers 1-9 on the } \\
\text { grid so that the } \\
\text { difference between } \\
\text { joined squares is } \\
\text { odd. }\end{array}$ \\
\hline
\end{tabular}

${ }^{1} \mathrm{NRICH}(2019 \mathrm{a}),{ }^{2} \mathrm{NRICH}(2019 \mathrm{~b})$

The study group children were chosen by the teachers. Selection was based on the teachers' assessments of children who, in previous lessons, had not demonstrated PiMR. These assessments included struggling to verbalise reasoning, giving up and not overcoming being stuck. The teachers and children discussed in this article are: Ms Parry, Michelle and Grace (school 1) in vignette 1; Mr Hall, Alice and Ruby (school 2 ) in vignettes 2 and 3 (pseudonyms). 


\section{Methods}

The state aspects of cognition, affect and conation are internal mental processes that might be inferred through external behaviours. This presented challenges for collecting and analysing data because there was no guaranteed correlation between internal processes and observable indicators. To mitigate this limitation, I used multiple data collection tools to enable triangulation. Data generated in mathematics lessons from direct observation, audio records and photographs were collated in lesson transcripts. Transcripts were also made of interviews with children that followed each lesson. Table 2 summarises the data collection methods.

Table 2: Summary of data and collection methods

\begin{tabular}{|l|l|l|l|}
\hline \multirow{2}{*}{ Domain } & \multicolumn{2}{|c|}{ Lesson observation } & \multicolumn{1}{|c|}{ Post-lesson interview } \\
\cline { 2 - 3 } & \multicolumn{1}{|c|}{ Direct observation } & \multicolumn{1}{c|}{ Audio records } \\
Cognitive & $\begin{array}{l}\text { Use of mathematical reasoning processes, } \\
\text { e.g. specialising } \\
\text { Mathematical representations } \\
\text { (photographed) }\end{array}$ & $\begin{array}{l}\text { Dialogue relating to reasoning } \\
\text { processes, e.g. generalising: } \\
\text { "It's always..." }\end{array}$ & $\begin{array}{l}\text { Explanations of } \\
\text { mathematical } \\
\text { reasoning }\end{array}$ \\
\hline Affective & $\begin{array}{l}\text { Facial expressions, e.g. raising eyebrows } \\
\text { Body position, e.g. head close to work } \\
\text { Pace of construction of representations }\end{array}$ & $\begin{array}{l}\text { Oral expressions and } \\
\text { utterances, e.g. groaning } \\
\text { Tone/pace of oral expression }\end{array}$ & $\begin{array}{l}\text { Discussions of } \\
\text { emotions experienced } \\
\text { during lessons }\end{array}$ \\
\hline Conative & $\begin{array}{l}\text { Focus of engagement } \\
\text { Actions relating to focus/change of focus } \\
\text { Movement between/stasis within } \\
\text { reasoning processes }\end{array}$ & $\begin{array}{l}\text { Dialogue relating to: } \\
\text { - focus/change of focus, e.g. } \\
\text { "let's try and make...." } \\
\text { - self-regulation, e.g. "That } \\
\text { didn't work, let's try..." }\end{array}$ & $\begin{array}{l}\text { Explanations of: } \\
\text { focus, rationale for } \\
\text { focus } \\
\text { reasons for changing } \\
\text { focus }\end{array}$ \\
\hline
\end{tabular}

I utilised the Conceptual Framework to create three coding categories with related analytic codes and sub-codes (Table 3). In the affective events category, I drew on terms from Goldin (2000); however, as he synthesised these from informal observations rather than empirical research, I derived the emotion sub-codes from data in my study to encode children's affective states. The resulting sub-codes reflect the data corpus in my overarching study; these may need to be augmented in future studies.

Table 3: Analytic codes

\begin{tabular}{|c|c|c|}
\hline Category & Code & Sub-code \\
\hline \multirow{5}{*}{ Cognition } & Specialising & Random trial(s); systematic trial(s) \\
\hline & Spotting patterns & Awareness of pattern/relationship \\
\hline & Conjecturing & Forms conjecture; tests conjecture; adjusts conjecture \\
\hline & Generalising & Forms generalisation \\
\hline & Convincing & $\begin{array}{l}\text { Considers why a conjecture/generalisation might be true/false } \\
\text { Uses logical language constructs in argument } \\
\text { Argument anchored in relevant mathematical properties }\end{array}$ \\
\hline
\end{tabular}




\begin{tabular}{|l|l|l|}
\hline & & Argument based on data \\
\hline Affect & $\begin{array}{l}\text { Demonstration of } \\
\text { affect }\end{array}$ & $\begin{array}{l}\text { Emotion: annoyance; despondency; disappointment; enjoyment; } \\
\text { exasperation; excitement; frustration; pride; puzzlement; satisfaction } \\
\text { Change in emotion }\end{array}$ \\
\hline \multirow{3}{*}{ Conation } & Active-goal & $\begin{array}{l}\text { Focus of engagement: creating solutions; seeking patterns; applying } \\
\text { patterns/relationships; describing generalisation; explaining why } \\
\text { generalisation is true; unrelated to reasoning activity }\end{array}$ \\
\cline { 2 - 4 } & Striving & $\begin{array}{l}\text { Movement between reasoning processes, e.g. from specialising to spotting } \\
\text { patterns } \\
\text { Persistent or repetitious behaviours, e.g. repeated specialising }\end{array}$ \\
\cline { 2 - 3 } & Self-regulation & $\begin{array}{l}\text { Cognitive self-regulation } \\
\text { Affective self-regulation }\end{array}$ \\
\hline
\end{tabular}

Analysis began by focusing on moments when children demonstrated PiMR or a lack of PiMR (encoded: striving). The former was evident in the movement between reasoning processes. The latter, whilst characterised by striving to keep going, was evident through limited movement between reasoning processes or stasis in one process. Given the focus on barriers to PiMR, I then analysed the cognitiveaffective-conative circumstances where there was evidence of persistent use of reasoning processes, or where reasoning processes did not progress to forming convincing arguments about generalisations. Here I sought to identify the difficulties children encountered during mathematical reasoning and to explain the circumstances in which these became barriers to PiMR.

Merriam (1995) argues that reliability in qualitative research concerns striving for dependability or consistency between the data and findings. I used three methods to strengthen the reliability of the study: triangulation (discussed at the beginning of this section), member checking and intra-rater reliability.

Member checking (Merriam, 1995) was important to support the development of consistent interpretations across multiple data sources; I approached this in two ways. First, during post-lesson interviews, I sought to gain the children's interpretation of what had happened and why. Second, in addition to teaching the lessons, the teachers read the observation and interview transcripts; the teachers and I met following each research lesson to discuss the data and its consistency with our initial interpretations.

As this was a small-scale, sole-researcher study, inter-rater reliability was not used. To reduce the impact of this limitation and to develop consistent application of codes, I conducted two waves of coding to enhance intra-rater reliability. Wave one took place immediately following the data collection and member checking processes for each lesson. Wave two coding took place on completion of data 
collection; I checked all data to ensure coding consistency, to finalise the sub-codes in the Demonstration of Affect code, and to review coding decisions made during wave one coding.

\section{Findings}

This section reports on the children's responses to mathematical reasoning activities in three vignettes; each details the reasoning activity, materials provided, children's seating arrangements, teacher's focus for the lesson and the children's responses.

\section{Vignette 1: Michelle and Grace's responses to the Magic Vs activity}

Ms Parry introduced Magic Vs (Table 1) by displaying two sets of the numbers 1-5 in V-formations (Fig. 2). She told the class that one V-formation was magic, the other was not. The children were asked to: identify which $V$ was magic with justification; explore constructing further magic $V s$ and form generalised statements with explanations as to why these were true.

a

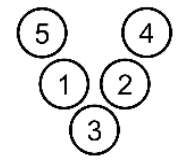

b

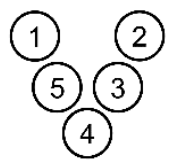

Fig. 2 Initial problem displayed on board

The class established in the first five minutes of the lesson that arrangement (a) in Fig. 2 was the magic $V$ of the pair because each arm of the V summed to the same total. Ms Parry asked the class to explore whether other arrangements could be found that were magic using the numbers 1-5. They were given a sheet with empty $\mathrm{V}$-arrangements to record their thinking.

Michelle and Grace were in adjacent seats. Immediately after Ms Parry had explained the activity, Michelle appeared to understand that one criterion was that only the digits 1-5 could be used:

$\begin{array}{ll}\text { Grace } & \text { Shall we do } 1 \text { to } 10 ? \\ \text { Michelle } & \text { But we have to do } 1 \text { to } 5\end{array}$

Following this exchange, the pair created two solutions that they believed to be successful as the arms of each V summed to the same total; however, they used the numbers $1-6$, first excluding 2 , then excluding 4, instead of the numbers 1-5 (Fig. 3).

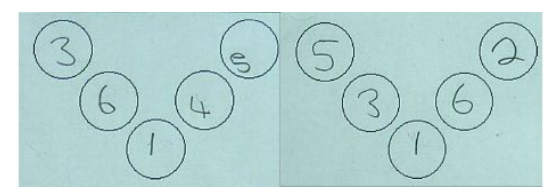

Fig. 3 Michelle and Grace's first two solutions 
Michelle then made the suggestion:

Let's try and make [each arm] 10

In this moment, Michelle and Grace's active-goal was to achieve a pre-determined total for each arm rather than using the given numbers to create equal totals for each arm; the pair did not appear to be aware of their misapplication of the criterion to use the numbers 1-5 despite class discussions that centred on these numbers. This led to other arrangements, only some of which correctly used the numbers 1-5, that the pair regarded as solutions (Fig. 4).

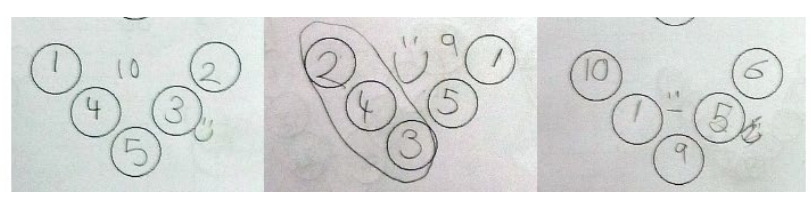

Fig. 4 Michelle and Grace's V arrangements - arms totalling 10, 9 and 20

Michelle and Grace's difficulty in applying the activity criteria meant that not all the solutions that they regarded as successful were valid. With a mix of valid and invalid solutions to compare, they were unable to seek patterns. Consequently, they did not form and test conjectures, for example, about the location of odd and even numbers or the number of solutions, nor form generalisations about these.

Whilst Michelle and Grace's difficulty arose from their misapplication of the original activity criteria, their lack of cognitive self-regulatory strategies to monitor their application of one criterion limited their capacity to realise and address the difficulty. Their focus was on creating solutions. Had it been on pattern spotting, they could have realised that there were few emerging patterns, and this could have triggered the application of cognitive self-regulatory strategies.

Whilst Michelle and Grace's lack of cognitive self-regulation did not provide the stimulus to shift their active-goal from creating solutions to spotting patterns, there was another, perhaps surprising, factor that sustained their active-goal of creating solutions; they seemed to derive enjoyment from creating apparently (but not) successful solutions, which Ms Parry remarked on near the end of the lesson:

$$
\begin{array}{ll}
\text { Ms Parry } & \text { Can I just tell you something I'm noticing? Both of you have got massive grins on your } \\
\text { faces which is so good, why is that? } \\
\text { Grace } & \text { [giggles] } \\
\text { Michelle } & \text { We like it [grinning]. }
\end{array}
$$

Michelle and Grace's enjoyment could be regarded as a positive emotional state, and this was reinforced in teacher feedback. However, in this instance, positive affect was not enabling and could have acted to constrain Michelle and Grace's PiMR. Malmivuori (2006) argues that active regulation of 
affect involves taking cognitive actions following the conscious monitoring of emotions, for example, deciding to adopt a different course of action following awareness of experiencing frustration. However, the experience of enjoyment, a pleasurable emotion, may have reinforced existing actions to prolong pleasure. If their active-goal had been noticing patterns rather than creating solutions, it is possible that they could have experienced frustration at the lack of emerging patterns. This could have stimulated active regulation of affect (Malmivuori) and a self-regulatory response that was enabling in facilitating PiMR.

\section{Vignette 2: Alice and Ruby's responses to the Paths Around the Pond activity}

Mr Hall introduced Paths around a Pond (Table 1 ) by modelling the $1^{2}$ pond/path using images of Cuisenaire rods on the board. The children were provided with Cuisenaire rods to construct representations of the ponds/paths and to support them to develop awareness of potential structural patterns in the sequence (and hence overcome one barrier that Michelle and Grace encountered in Vignette 1). Following construction, the children were given pencils and paper to record the corresponding numeric sequence.

Alice and Ruby were in adjacent seats. Initially they made random trials, selecting and arranging four $10 \mathrm{~cm}$ rods into an oblong to represent the path and continuing this construction partly by creating successive concentric oblongs within the original (Fig. 5).

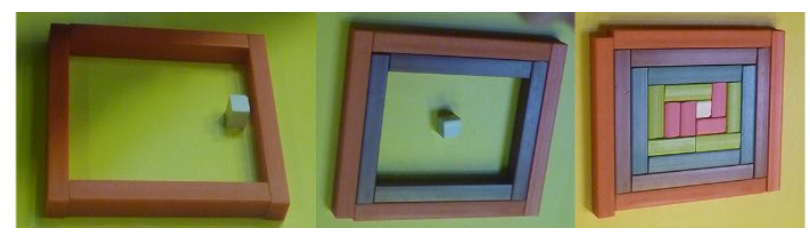

Fig. 5 Alice and Ruby's initial trials

Each then seemed to self-regulate. Alice realised that these trials did not fit the criterion to create a square pond:

That's really weird, it doesn't work

In the post-lesson interview, Ruby explained her approach following these unsuccessful trials:

I put the centre first and then the outside - I think I found it easier doing it that way

This may have helped her to ensure that the pond was square before constructing the path. In their next trial, they adopted Ruby's idea and constructed the $9^{2}$ pond using nine $9 \mathrm{~cm}$ rods, surrounded by a square path of four $10 \mathrm{~cm}$ rods. Finally, they created a set of systematically ordered, systematically 
constructed ponds/paths where each pond was represented by $n$ rods of length $n$, and each path by 4 rods of length $n+1$ (Fig. 6).

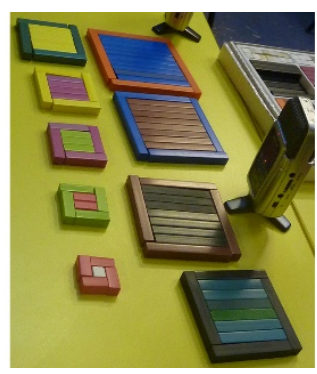

Fig. 6 Alice and Ruby's systematic construction and ordering of trials

During this construction phase Alice seemed to experience enjoyment and excitement on realising the emerging pattern:

They go up in steps [said in excited tones]

Oh my god, I've got a pattern [cheers and claps]

$\mathrm{Mr}$ Hall then re-focused the activity from creating and seeking patterns in the Cuisenaire constructions, to tabulating the size of the ponds and paths and seeking numerical patterns. Alice and Ruby did not explore numeric tabulation of the ponds and surrounding paths and hence were not able to seek numerical patterns. Instead, for the remaining 22 minutes of the lesson, they used the rods to make unrelated tower constructions. They seemed to enjoy this; in the post-lesson interview Alice described the lesson as:

\section{Really fun}

When I asked why they did not use the time they had to tabulate their findings and seek numerical patterns, Ruby replied:

I thought we didn't need to do it on the paper because we'd already done it

In the post-lesson interview, Ruby explained the colour pattern that they had noticed and applied to construct the systematically arranged and ordered sequence:

The red's on the outside there $\left[1^{2}\right.$ pond $]$ so it's on the inside there $\left[2^{2}\right.$ pond $]$. Then the green's on the outside so then it's on the inside.

Alice further remarked that:

Mr Hall said there were two patterns, there's a number pattern and a colour pattern. 
However, despite knowing that there was a numerical pattern to discover and Mr Hall endeavouring to focus the children's active-goals to enable the emergence of numerical patterns, Alice and Ruby made no further progress in their reasoning about the relationship between pond and path size. Consequently, they were not able to form generalisations and related convincing arguments.

The purpose here was to develop the children's awareness of physical and numeric patterns to promote generalising about this sequence. However, Alice and Ruby did not appear to share this focus, attending instead to physically constructing trials and spotting patterns in these constructions. This formed their active-goal; they strived to complete the ordered set of Cuisenaire ponds/paths, gained enjoyment from this and when completed, their focus on the activity ceased.

Whilst this may be an example of the difficulty that Ellis (2007) describes in utilising observed patterns as a platform for generalisation, the affect expressed by Alice and Ruby appears significant in creating a barrier to persevering in mathematical reasoning; their enjoyment and excitement in creating systematic constructions seemed to lead to further, unrelated, construction rather than to alternative processes that could have progressed their reasoning in this activity, such as generalising the constructed pattern or seeking and generalising numeric patterns.

The children's barrier to PiMR arose from their active-goal of physically constructing ponds/paths. Despite the teacher's intervention to focus on the numerical pattern, the pair may not have seen the purpose in this, perceiving instead the constructed sequence as the end-point. Their enjoyment in successful construction seemed to create a desire to strive for extended construction with no evidence of self-regulation in response to teacher guidance or the outcomes of construction.

\section{Vignette 3: Alice and Ruby's responses to the Number Differences activity}

To support children to overcome the barrier of not utilising observed patterns to support generalisations with explanations, Mr Hall introduced Number Differences (Table 1) with the goal of forming generalisations with convincing arguments as to why these were true:

[You need to] identify and explain a successful pattern.

He set a maximum of finding ten solutions, as with this number it was likely that the children would have established a viable pattern and could then focus on explaining why this worked.

The children were provided with 1-9 number cards to support their manipulation and construction of solutions. 
Alice and Ruby were in adjacent seats. During the first four minutes of the activity, they began to arrange the cards and created two sucessful solutions (Fig. 7).

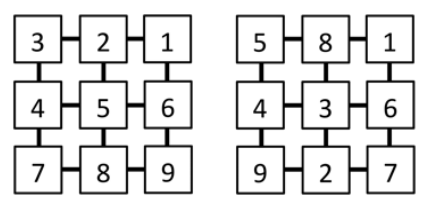

Fig. 7 Representations of Alice and Ruby's first two solutions

The pair continued to generate successful solutions and expressed enjoyment in this; they kept an oral running total of the number of solutions, they cheered with delight at each successful trial and worked quickly to construct new trials:

$\begin{array}{ll}\text { Alice } & \text { Woo, we got it } \\ \text { Ruby } & \text { We've got } 5 \text { [excited, pleased tone] } \\ \text { Alice } & \text { We need } 3 \text { more [solutions] } \\ \text { Ruby } & \text { Yes, come on } \\ \text { Alice } & \text { We've done } 12 \text { [claps and cheers] }\end{array}$

During this exploration, the pair formed a conjecture that odd numbers needed to be positioned in the centre of the grid and $\mathrm{Mr}$ Hall continually reinforced the limit on the number of solutions found, the need to generalise the emerging patterns and to explain why these worked:

Alice Shall we try 9 in the middle? What number shall we put in the middle? What's odd?

Ruby Put all the odd numbers in the middle

Mr Hall If you have 10 solutions and a pattern that works, then your job is to explain that pattern and why it works. It's not who's got the most

Alice [Groans]

Mr Hall's intervention was a conscious action to overcome the difficulty as in Reid (2002), that children may not have the expectation to form generalisations and reasons why they are true. Whilst this instruction was met with a groan from Alice, indicating her disappointment at being asked to stop creating solutions, when they had established thirteen solutions, Alice and Ruby shifted their focus to developing a description and explanation of patterns.

Ruby's written description of the generalisation (Ruby's emphasis):

First we found that the odd numbers go in the middle one by one. Then all the other odd numbers go in the corners, and the even numbers go in the spaces left.

Alice's written description and partial explanation of the generalisation: 
it works when you put a odd number in the middle and odd numbers in the corners because oddeven=odd. the space in the middle is going to be odd but you have to use the right tow [sic, two] numbers.

Of note in both pieces is the children's capacity to generalise the pattern of how to generate successful solutions. Alice had also begun to explain why the arrangement worked by anchoring her argument (Lithner, 2008) in the difference between adjacent odd and even numbers. However, she did not consider why, for the numbers 1-9, odd numbers, rather than even, had to be positioned in the corners and centre of the grid.

The children's focus on forming convincing arguments about why their generalisations were true then ceased and both returned to applying the generalisation to make many more solutions as quickly as they could:

Alice One more to go and then we've got 23 [solutions]

In this lesson, there were opportunities for Alice and Ruby to produce assertions, reach conclusions and develop justifications (Lithner, 2008). Whilst the pair remained focused throughout, at the point when they were well positioned to construct arguments to explain patterns, their active-goal reverted to creating examples. This appeared to be influenced by their enjoyment in striving towards an active-goal of making solutions and may have enabled them to believe that they were conforming to classroom norms by continuing to engage with the activity (Fredricks et al., 2004). Nevertheless, although engaged, their PiMR was limited by the absence of an active-goal to construct convincing arguments. This was further compounded by a lack of self-regulatory approaches that would have enabled them to realise that their behaviours were repetitious and not aligned with teacher guidance. This resulted in their being unable to use their understanding of the generalised pattern as a foundation for explaining the generalisation (Ellis, 2007).

\section{Discussion}

This paper posed two questions: what difficulties do children need to overcome in order to persevere in mathematical reasoning? What are the conditions under which the difficulties become barriers to PiMR? This section summarises and builds on the findings relating to question 1 and examines question 2 .

Eight known difficulties that children can experience during mathematical reasoning (discussed in the conceptual framework) are summarised in Table 4 alongside the barriers to PiMR that the children in these vignettes did not surmount during the lessons. 
Table 4: Summary of findings in relation to known difficulties in mathematical reasoning

\begin{tabular}{|c|c|c|}
\hline Domain & $\begin{array}{l}\text { Difficulties in mathematical reasoning } \\
\text { discussed in literature }\end{array}$ & Barriers to PiMR observed in vignettes (V) \\
\hline \multirow{3}{*}{ Cognitive } & $\begin{array}{l}\text { Difficulty in utilising observed patterns as } \\
\text { a platform for generalisation (Ellis, 2007). }\end{array}$ & $\begin{array}{l}\text { V2: Alice and Ruby did not use patterns observed as } \\
\text { platform for generalisation. }\end{array}$ \\
\hline & $\begin{array}{l}\text { Difficulty creating convincing arguments } \\
\text { about why a generalisation might be true } \\
\text { (Ellis, 2007). }\end{array}$ & $\begin{array}{l}\text { V3: Alice and Ruby described the generalisation. Alice } \\
\text { partially explained why the generalisation was true; } \\
\text { Ruby gave no explanation about why it was true. }\end{array}$ \\
\hline & $\begin{array}{l}\text { Not expecting to explain reasons why } \\
\text { mathematical pattern occurs (Reid, 2002). }\end{array}$ & None observed. \\
\hline Affective & $\begin{array}{l}\text { Difficulty arising from negative affective } \\
\text { pathway (Goldin, 2000). }\end{array}$ & None observed. \\
\hline \multirow{4}{*}{ Conative } & $\begin{array}{l}\text { Habitual or persistent behaviour (Huitt } \\
\text { and Cain, 2005; Tanner and Jones, 2003; } \\
\text { Williams, 2014). }\end{array}$ & $\begin{array}{l}\text { V3: Alice and Ruby returned to creating further } \\
\text { solutions having described but not fully explained their } \\
\text { generalisations. }\end{array}$ \\
\hline & $\begin{array}{l}\text { Difficulty in applying self-regulatory } \\
\text { approaches (Goswami, 2015). }\end{array}$ & $\begin{array}{l}\text { V1: Michelle and Grace understood the activity criteria } \\
\text { but did not self-regulate to correct their misapplication } \\
\text { of one criterion. }\end{array}$ \\
\hline & $\begin{array}{l}\text { Adhering to classroom engagement norms } \\
\text { (Fredricks et al., 2004) in the absence of a } \\
\text { focus on relevant mathematical concepts } \\
\text { or reasoning processes. }\end{array}$ & $\begin{array}{l}\text { V3: Alice and Ruby's lack of focus on constructing } \\
\text { convincing arguments despite engagement in the } \\
\text { activity. }\end{array}$ \\
\hline & $\begin{array}{l}\text { Automatic self-regulation; affective } \\
\text { responses overriding self-regulation } \\
\text { (Malmivuori, 2006). }\end{array}$ & $\begin{array}{l}\text { V3: Alice and Ruby's enjoyment of creating successful } \\
\text { solutions fostered habitual behaviours and on-going } \\
\text { creation of solutions. }\end{array}$ \\
\hline
\end{tabular}

There are notable similarities in the findings: the children's focus on creating solutions; their apparent enjoyment and excitement whilst engaging with activities involving mathematical reasoning; repetitious use of the specialisation process instead of other mathematical reasoning processes; and apparent lack of awareness at having encountered a difficulty in mathematical reasoning. These features of the children's responses to activities involving mathematical reasoning formed a cognitive-affectiveconative cycle that acted to limit the children's PiMR.

In each vignette, the children's initial active-goal was to create solutions and they applied random and systematic specialisation processes to achieve this. They derived enjoyment and excitement from specialising, but these emotions did not seem to arise from selecting an effective approach or new insights as Goldin (2000) postulates, rather from the generation of valid solutions or those that they believed to be valid.

Mason et al. (2010) argue that random and systematic specialising are valid starting points to generate data and to prepare the ground for generalising. However, the enjoyment arising from creating solutions seemed to inspire the children to persist in striving to create further solutions. This led to a cycle in 
which the children's active-goal of making solutions and enjoyment in the repetitions process of making solutions was not conducive to and did not result in PiMR.

To break out of this self-limiting cycle the children needed to be able to apply pro-active self-regulatory behaviours (Huitt and Cain, 2005; Tanner and Jones, 2003) to realise that they had encountered difficulties in pursuing a line of mathematical reasoning. However, they appeared to be operating within limited self-regulatory systems in which self-regulation was over-ridden by habitual responses. This resulted in automatic affective regulation (Malmivuori, 2006) and continuing engagement with repetitious actions towards an active-goal that was not conducive to PiMR. Fig. 8 represents the cycle of cognition-affect-conation that acted to reinforce the children's limited PiMR.

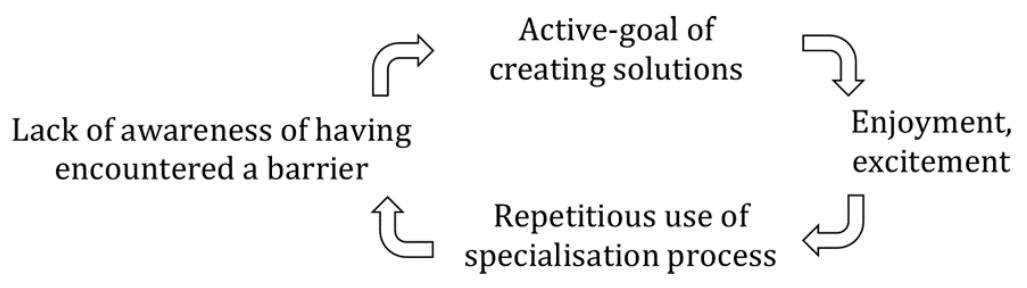

Fig. 8 Cognitive-affective-conative cycle reinforcing limited PiMR

Whilst the children's affective responses could be described as positive, they were not comparable with the rapidly changing range of emotions described in Goldin's (2000) enabling affective pathway. In his pathway, pleasure arises having employed strategies to overcome periods of bewilderment and frustration, and leads to elation following breakthrough moments. Experiencing a broader range of emotions, particularly those that may not be comfortable such as frustration or bewilderment, is a potentially important catalyst for active regulation of affect (Malmivuori, 2006); for example, frustration could stimulate reflection on and self-regulation of reasoning processes. However, the study children's affective pathways comprised a limited range of seemingly positive emotions. Their lack of a broader range of emotions during mathematical reasoning, particularly those that are seemingly less comfortable, appears significant as it may have hindered their exposure to a potential affective catalyst for self-regulation.

Malmivuori's (2006) automatic affective regulation operates within a weak self-regulatory system, in which habitual affective responses over-ride self-regulation, and this seems a reasonable explanation of the children's responses. However, whereas Malmivuori exemplifies this in a situation in which higher order thinking processes are hindered by strong negative emotion responses, in these vignettes, mathematical reasoning was hindered by seemingly positive, desirable emotions. This meant that when the children encountered difficulties in reasoning, their emotions acted to maintain their engagement 
and fuel the self-limiting cycle (Fig. 8), creating a barrier that they did not overcome within the duration of the lessons. This idea, that enjoyment created a barrier to PiMR, seems both counter-intuitive and contrary to literature. For example, in Goldin's (2000) enabling affective pathway, there is bi-directional interplay between state-related emotion and cognition, with enabling emotions impacting thinking and vice-versa, and Hannula (2019) and Schukajlow et al. (2012) report a similar positive correlation between trait-related affect and achievement. However, in this study there is evidence that seemingly positive emotions can act as a barrier to mathematical reasoning.

There is a further consequence to the children's affective responses of enjoyment and excitement and the resulting self-limiting cycle. They did not show outward displays of being stuck; there were no expressions of frustration or requests for help to indicate self-knowledge of having met a difficulty. This was perhaps not surprising since they seemed satisfied with the activity as they perceived it. However, a consequence of this was that there were no explicit indicators for the teachers that the children had met difficulties in reasoning. I discussed above how the children's enjoyment inhibited their self-regulatory process and hindered their awareness of having encountered a difficulty. Children's expressions of enjoyment, in conjunction with their engagement, might also act to conceal their barriers to PiMR from the teacher. Teachers may need to look beyond expressions of frustration or being stuck, and not be misled by expressions of enjoyment or indications of engagement and striving, to assess whether children have encountered a barrier to PiMR. As children's affective and conative responses may mask their experience of difficulty, teachers could look to their cognitive responses. Specialisation (Mason et al., 2010), generating examples through making trials, was the main mathematical process used and was applied repeatedly. Whilst some repeated specialisation is needed to generate data from which patterns are determined, for the study children, making trials having established a pattern became their dominant mathematical process; this was an indicator of their having encountered a barrier to PiMR. Teachers could look for repeated specialising as a cue to adopt pedagogic approaches, some of which are discussed in Barnes (2019), that support children to overcome this barrier and to progress from specialisation towards generalising and forming convincing arguments.

\section{Conclusions}

This study extends the literature about difficulties in mathematical reasoning in three ways. First, it revealed the role that seemingly positive, desirable and stable emotions can have in limiting selfregulatory behaviours and creating barriers to PiMR; this appears to be counter to the reciprocal relationship between enjoyment and achievement in mathematics learning (Hannula, 2019; Schukajlow 
et al., 2012). Second, the study recognised the importance of the children's active-goals, and in particular, how an active-goal of creating solutions, whilst a useful starting point in activities involving reasoning, can reinforce habitual, repetitious behaviours for children operating within weak selfregulatory systems. In this situation, generic perseverance guidance, such as keep going, would act to exacerbate the barrier. Finally, a new self-limiting cognitive-affective-conative cycle (Fig. 8) that acts to reinforce children's pre-existing limited PiMR is proposed. Future research in the field could continue to understand this cycle and its ramifications.

The focus on questions addressing the difficulties children need to overcome to persevere in mathematical reasoning and when these became barriers to PiMR has enabled this study to make explicit the counter-intuitive finding that enjoyment can create barriers to PiMR. This has implications for teacher educators. The findings can be applied in designing professional development programmes to support teachers to better understand the roles that active-goals, habitual specialising and enjoyment can play in creating barriers to PiMR for some children, and to recognise children's application of specific mathematical reasoning processes. This could help generalist primary (elementary) teachers to develop and apply specific strategies to develop children's PiMR, rather than relying on generic perseverance teaching strategies that may exacerbate barriers to PiMR.

\section{References}

Ball, D., \& Bass, H. (2003). Making Mathematics Reasonable in School. In W. Kilpatrick (Ed.), A Research Companion to Principles and Standards for School Mathematics (pp. 27-44). Reston, VA: National Council of Teachers of Mathematics.

Barnes, A. (2019). Perseverance in mathematical reasoning: The role of children's conative focus in the productive interplay between cognition and affect. Research in Mathematics Education, 21(3), 271-294.

DeBellis, V. A., \& Goldin, G. A. (2006). Affect and meta-affect in mathematical problem solving: A representational perspective. Educational Studies in Mathematics, 63(2), 131-147.

Di Martino, P., \& Zan, R. (2011). Attitude towards mathematics: A bridge between beliefs and emotions. ZDM-The International Journal on Mathematics Education, 43(4), 471-482.

Dweck, C. S. (2000). Self-Theories: Their role in motivation, personality, and development (Essays in social psychology). Hove: Psychology Press.

Ellis, A. B. (2007). Connections between generalizing and justifying: Students' reasoning with linear relationships. Journal for Research in Mathematics Education, 38(3), 194-229.

Ely, M., Vinz, R., Downing, M., \& Anzul, M. (1997). On writing qualitative research: Living by words. London: Falmer Press.

Fredricks, J., Blumenfeld, P., \& Paris, A. (2004). School engagement: Potential of the concept, state of the evidence. Review of Educational Research, 74(1), 59-109.

Goldin, G. (2000). Affective pathways and representation in mathematical problem solving. Mathematical Thinking and Learning, 2(3), 209-219. 
Goldin, G. A., Epstein, Y. M., Schorr, R. Y., \& Warner, L. B. (2011). Beliefs and engagement structures: Behind the affective dimension of mathematical learning. ZDM-The International Journal on Mathematics Education, 43(4), 547-560.

Goswami, U. (2015). Children's Cognitive Development and Learning. York: Cambridge Primary Review Trust.

Hannula, M. (2011). The structure and dynamics of affect in mathematical thinking and learning. Paper presented at the Proceedings of the Seventh Congress of the European Society for Research in Mathematics Education, University of Rzeszów, Poland.

Hannula, M. (2012). Exploring new dimensions of mathematics-related affect: Embodied and social theories. Research in Mathematics Education, 14(2), 137-161.

Hannula, M. (2019). Young learners' mathematics-related affect: A commentary on concepts, methods, and developmental trends. Educational Studies in Mathematics, 100(3), 309-316.

Hiebert, J. (2003). Signposts for Teaching Mathematics Through Problem Solving. In F. K. Lester (Ed.), Teaching Mathematics through Problem Solving: Prekindergarten-grade 6 (pp. 53-61). Reston, VA: NCTM.

Huitt, W., \& Cain, S. (2005). An overview of the conative domain. Educational Psychology Interactive. http://www.edpsycinteractive.org/papers/conative.pdf. Accessed 13 December 2019.

Lakatos, I. (1976). Proofs and refutations: The logic of mathematical discovery. Cambridge: Cambridge University Press.

Lithner, J. (2008). A research famework for creative and imitative reasoning. Educational Studies in Mathematics, 67(3), 255-276.

Malmivuori, M. (2006). Affect and self-regulation. Educational Studies in Mathematics, 63(Special Issue), 149-164.

Mason, J., Burton, L., \& Stacey, K. (2010). Thinking mathematically (2nd ed.). Harlow: Pearson.

Mason, J., Stephens, M., \& Watson, A. (2009). Appreciating mathematical structure for all. Mathematics Education Research Journal, 21(2), 10-32.

Merriam, S. B. (1995). What can you tell from an $\mathrm{N}$ of 1 : Issues of validity and reliability in qualitative research. PAACE Journal of Lifelong Learning, 4, 51-60.

Merriam, S. B. (1998). Qualitative research and case study applications in education. Jossey-Bass: California.

Mueller, M. F., Yankelewitz, D., \& Maher, C. (2010). Promoting student reasoning through careful task design: A comparison of three studies. International Journal for Studies in Mathematics Education, 3, 135-156.

NRICH (2019a). Magic Vs. Nrich, University of Cambridge. http://nrich.maths.org/6274. Accessed 20 June 2019.

NRICH (2019b). Number Differences. Nrich, University of Cambridge. http://nrich.maths.org/2790/note. Accessed 20 June 2019.

Özcan, Z. Ç. (2016). The relationship between mathematical problem-solving skills and self-regulated learning through homework behaviours, motivation, and metacognition. International Journal of Mathematical Education in Science and Technology, 47(3), 408-420.

Pólya, G. (1959). Mathematics as a subject for learning plausible reasoning. Mathematics Teacher, 52, 79.

Reid, D. A. (2002). Conjectures and refutations in grade 5 mathematics. Journal for Research in Mathematics Education, 33(1), 5-29.

Schukajlow, S., Leiss, D., Pekrun, R., Blum, W., Müller, M., \& Messner, R. (2012). Teaching methods for modelling problems and students' task-specific enjoyment, value, interest and self-efficacy expectations. Educational Studies in Mathematics, 79(2), 215-237. 
Somekh, B. (2006). Action research: A methodology for change and development. Maidenhead: Open University Press.

Snow, R., Corno, L., \& Jackson, D. (1996). Individual differences in affective and conative functions. In D. Berliner, \& R. Calfee (Eds.), Handbook of educational psychology (pp. 243-310). London: Prentice Hall.

Stylianides, G. (2008). An analytic framework of reasoning-and-proving. For the Learning of Mathematics, 28(1), 9-16.

Tanner, H., \& Jones, S. (2003). Self-efficacy in mathematics and students' use of self-regulated learning strategies during assessment events. Proceedings of the 27th Conference of the International Group for the Psychology of Mathematics Education, 275-282.

Williams, G. (2014). Optimistic problem-solving activity: Enacting confidence, persistence, and perseverance. ZDM-The International Journal on Mathematics Education, 46(3), 407-422.

Zimmerman, B. J., \& Schunk, D. H. (2011). Handbook of Self-Regulation of Learning and Performance. London: Routledge. 